\title{
A Study on the Effects of Switch Intention on Customer Attribution: the Case of the Galaxy, Xiaomi and Brand Type
}

\author{
Huifeng Pan ${ }^{1}$, Hee-Young Son ${ }^{2}$, Sang-Kyu Park ${ }^{3}$ and Man-Su Kang ${ }^{4}$ \\ ${ }^{1}$ Beijing Institute of Graphic Communication; Post-Doctoral Research Station in \\ Business Administration of TsingHua University, Beijing, China \\ ${ }^{2}$ Team of Research \& Development, Korea Institute of Startup \& \\ Entrepreneurship Development, Daejeon 302-120, Korea \\ ${ }^{3}$ Department of Business Administration, Kangwon National University, \\ Chuncheon-si 200-701, Korea \\ ${ }^{4 *}$ Team of Business Planning, Seoul of Credit Guarantee Foundations, Seoul \\ 04130, Korea (Corresponding Author) \\ 1282123934@qq.com, ${ }^{2}$ sonhy@kised.or.kr, ${ }^{3}$ skpark@kangwon.ac.kr, \\ 4*jazz@kangwon.ac.kr
}

\begin{abstract}
This study includes a survey conducted by an entrusted internet research agency among smart-phone users of Samsung Galaxy which aims to secure its market share in the Chinese smart-phone market as well as the global market and Xiaomi that is taking the lead of the Chinese smart-phone market in order to examine the effect of monetary value, non-monetary value, user satisfaction, product trust, information reliability, attachment, commitment, and brand types on switch intention.

The analysis results are as follows: First, among the 7 attributes indicating the switch intention of Galaxy users, it turned out that non-monetary value, product trust, and commitment were statistically significant at the significance level of $\alpha=0.05$ while the rest were statistically insignificant at the significance level of $\alpha=0.05$. Second, among the 7 attributes indicating the switch intention of Xiaomi users, it turned out that user satisfaction, product trust, and commitment were statistically significant at the significance level of $\alpha=0.1$ while the rest were statistically insignificant at the significance level of $\alpha=0.1$. Lastly, among the 8 attributes indicating the switch intention of the general users, it turned out that user satisfaction, product trust, commitment and brand types were statistically insignificant at the significance level of $\alpha=0.1$ while the rest were statistically insignificant at the significance level of $\alpha=0.1$.

If enterprises that intend to release smart-phones in the Chinese smart-phone market need primary data for the establishment of marketing strategies differentiated from those of competitors, it is expected that these findings will be useful, which is the significance of this study.
\end{abstract}

Keywords: Switch Intension, Value, Satisfaction, Trust, Attachment, Commitment, Brand Type

\section{Introduction}

In June 2015, TrendForce [1] reported the current condition of the global smart-phone market during the second quarter. According to this report, among the major smart-phone manufacturers (5 companies), the market shares of the two Chinese brands - Wuawei and Xiaomi - are the third and fourth, respectively, while Samsung is the first and Apple the second. In the Chinese smart-phone market, however, the top 5 manufacturers are all Chinese enterprises: although the Chinese smart-phone market is becoming a field of 
competition among various smart-phone manufacturers such as Apple, Xiaomi, Samsung, Lenovo, and Wuawei, Chinese manufacturers still hold superiority when it comes to market shares. This is in line with the fact that in Korea, Samsung Galaxy is the unchallenged leader in the market, and this is probably because the people prefer the domestic brand to foreign brands because of their attachment to it.

As of the end of 2002, the number of mobile-phone users in China exceeded 0.266 billion, which is more than any other country including the U.S. In the Chinese mobilephone market, the era of Chinese smart-phones began in 2009 because of the 3G technology. In 2010, the number of 3G-based mobile phone users in China exceeded 87 million, and the number is still increasing. In 2001, the number of mobile phones produced in China was 1.13 billion, which indicates that the growth rate is $13.23 \%$ compared to the year 2020, and that the total output accounted for $70.6 \%$ of the entire amount of mobile phone shipments worldwide. The number of exported mobile phones was 0.885 billion, which is $16.75 \%$ higher than that in 2010 . Since then, the amount of shipment in China has increased up to 0.28 billion in 2011. As such, interest in 3G communication service has been gradually increasing among mobile phone users in China, and interest in smart-phone models released after the $3 \mathrm{G}$ generation have increased as well. The smart-phone market in China shows the highest growth rates in this business sector of China. Although the smart-phone market in China grows fast, Chinese smart-phone manufacturers have neglected quality surveys after production and new product development because of their inferior capabilities in areas of tests, quality improvement, and new technology development. In addition, various problems have occurred with regard to customer service after sales, guarantee of consumer rights, etc. Even the process of providing communication service for smart-phones involved leakage of customer information. As a result, the manufacturers are losing the trust of Chinese consumers while complaints are gradually increasing, which affects their switch intention substantially.

Changes in the Chinese smart-phone market stated above indicate that enterprises should grasp consumer behaviors in order to maintain competition superiority. As consumers express desires for changes and new items and manufacturers fail to satisfy all of such various pursuits and desires, it is necessary to analyze and properly handle attributes of Chinese consumers [2]. In addition, consumers would prefer brands that correspond to their values and are appropriate to express themselves. Once a certain brand is preferred, that is stamped in their memory, the level of preference tends to increase continually with switch intention disappearing gradually [3].

Accordingly, this study includes a survey conducted by an entrusted internet research agency among smart-phone users of Samsung Galaxy which aims to secure its market share in the Chinese smart-phone market as well as the global market and Xiaomi that is taking the lead of the Chinese smart-phone market in order to examine the effect of monetary value, non-monetary value, user satisfaction, product trust, information reliability, attachment, commitment, and brand types on switch intention.

The effect of monetary value, non-monetary value, user satisfaction, product trust, information reliability, attachment, commitment, and brand types that smart-phone users in the Chinese smart-phone market on their switch intention as well as the difference among variables are examined. The findings are expected to contribute to establish marketing strategies to secure competitive advantage over competitors in China. Additionally, if enterprises that intend to release smart-phones in the Chinese smartphone market need primary data for the establishment of marketing strategies differentiated from those of competitors, it is expected that these findings will be useful, which is the significance of this study. 


\section{Theoretical Background}

\subsection{Current Condition of the smart-phone Industry}

A smart-phone is "a device that features computer functions as well as phone-calling." The term, 'smart-phone,' became popular around the globe as Steve Jobs at Apple released 'i-phones.' The emergence of smart-phones has expanded the social area as they add various internet-based functions to mobile phone terminals such as documentation, emailing, online gaming, SNS, shopping, music, online banking, etc., regardless of the time and location.

Basic features of smart-phones include opened OS operation, applications/software download, 3G and LTE networking, environment similar to that of PCs (Synchronizing), and so forth. They play an important role of ICTs: It is possible to manipulate various items by means of a smart-phone through access to the internet such as smart refrigerator, smart bed, smart school bag, smart home, and smart car. The AOT-based technology to manipulate all possible things in connection with a smart-phone is being developed at present.

According to TrendForce [1], among the 5 major companies leading the global smartphone industry shown in $\langle$ Table 2-1>, the market share of Samsung in the second quarter of 2015 was $26.8 \%$ and Apple 16.4\%, which indicates that the world smart-phone market is led mainly by Samsung and Apple. The shares of the two Chinese brands - Wuawei and Xiaomi - were $7.8 \%$ and $5.9 \%$ respectively, which are the third and fourth. The Chinese smart-phone market, however, shows a different pattern: Chinese smart-phone brands account for the largest portion of the market.

As reported in <Table 2-2>, the market share of Wuawei in the second quarter of 2015 is $18.3 \%$, and Xiaomi $24.3 \%$, which are the first and second. Samsung and Apple are not even among the top five. This indicates that while the switch rates to Apple i-phones and Samsung Galaxy are low among Chinese smart-phone consumers, they rather prefer Chinese brands. <Table 2-1> and <Table 2-2> compare the global sales of smart-phones and sales within China. In the second quarter of 2015, China accounts for $41.3 \%$ of the entire smart-phone sales in the world. This shows that increasingly higher market shares in China will be a way for a smart-phone manufacturer to increase its general sales.

Table 2-1. Top 5 Global Smart-phone Brands by Shipments

\begin{tabular}{|c|c|c|c|c|}
\hline \multirow{2}{*}{ Company } & \multicolumn{2}{|c|}{ 2Q2015 } & \multicolumn{2}{|c|}{ 1Q2015 } \\
\hline & Ranking & Market share & Ranking & Market share \\
\hline Samsung & 1 & $26.8 \%$ & 1 & $26.8 \%$ \\
\hline Apple & 2 & $16.4 \%$ & 2 & $20.5 \%$ \\
\hline Huawei & 3 & $7.8 \%$ & 3 & $6.9 \%$ \\
\hline Xiaomi & 4 & $5.9 \%$ & 6 & $5.4 \%$ \\
\hline LG & 5 & $5.8 \%$ & 5 & $5.5 \%$ \\
\hline Others & - & $37.5 \%$ & - & $34.9 \%$ \\
\hline Shipment Total (Unit : K) & & 304,090 & & 298,440 \\
\hline
\end{tabular}


Table 2-1. Top 5 Chinese Smart-phone Brands by Shipments

\begin{tabular}{|c|c|c|c|c|}
\hline \multirow{2}{*}{ Company } & \multicolumn{2}{|c|}{ 2Q2015 } & \multicolumn{2}{|c|}{ 1Q2015 } \\
\hline & Ranking & Market share & Ranking & Market share \\
\hline Huawei & 1 & $18.3 \%$ & 1 & $18.9 \%$ \\
\hline Xiaomi & 2 & $14.3 \%$ & 3 & $14.7 \%$ \\
\hline Lenovo & 3 & $12.7 \%$ & 2 & $15.7 \%$ \\
\hline TCL & 4 & $10.0 \%$ & 4 & $9.2 \%$ \\
\hline OPPO & 5 & $8.4 \%$ & 5 & $8.7 \%$ \\
\hline Others & - & $36.3 \%$ & - & $32.8 \%$ \\
\hline Shipment Total (Unit : K) & & 125,500 & & 108,600 \\
\hline
\end{tabular}

\subsection{Switch Intention}

'Switch intention' is a personal conviction that one bears prior to action. The higher level of intention, the higher possibility of actual switch [4]. In terms of marketing, switch intention draws attention because customer secession causes sales and business profits to decrease as customers decide to use other services or products. With regard to such switch intention among customers, Lattin and McAlister [2] point out that as consumers would show switch intention because of their desires for changes and new items rather than dissatisfaction with purchased goods.

There have been exploratory researches on switch intention, specifically on causes of change in switch behaviors, by means of the CIT (Critical Incidents Technique). There are 8 major causes of switch behaviors: price, inconvenience, core service failure, failed service encounter, response to service failed, competition, ethical problem, and involuntary switching [5]. Besides, it is reported that financial, social, and psychological risks such as exploratory expenses, learning expenses, and cognitive expenses also affect switch behaviors [3]. The higher level of switch intention, the higher possibility of switch behaviors [6].

\subsection{Logistic Regression Analysis}

Logistic Regression Analysis, first named by Pierre Francois Verhulst [7], is a special type of regression analysis that is utilized when the dependent variable is a nominal scale. When the dependent variable has only two values, the common linear regression analysis is not appropriate [8]. For instance, in the case of the binary dependent variable: "there is/is no switch intention," this analysis method is utilized to find the best fit line for the relation between the dependent variable and independent variable (explanatory variable) when continuous variables such as monetary value, non-monetary value, user satisfaction, product trust, information reliability, attachment, and commitment are the independent variables (explanatory variable) and categorical variables such as brand type are the independent variable (explanatory variable).

Logistic Regression Analysis is divided into Quadratic Logistic Regression Analysis, Multiple Logistic Regression Analysis, and Conditional Logistic Regression Analysis. Quadratic Logistic Regression Analysis is the most fundamental Logistic Regression Analysis with two selective options for the dependent variable. Multiple Logistic Regression Analysis has three selective options for the dependent variable, each of which is independent to one another. Conditional Logistic Regression Analysis eases the explanatory variable conditions of Quadratic Logistic Regression Analysis and Multiple 
Logistic Regression Analysis. The number of selective options for the dependent variable is not taken into account.

\section{Setting of the Research Model}

Against the theoretical background presented above, the attribution of smart-phone customers in China was set as the independent variable, and switch intention as the dependent variable to determine whether or not there was switch intention. This type of research model utilizes the binary scale of Logistic Regression Analysis with dependent variables taken into account. As Logistic Regression Analysis has binary response variables, there is no need for conditions or assumptions that are essential for common regression analyses. Thus, the prediction probability can be calculated even if the response variable is not of continuous data that shows normal distribution. In addition, this analysis is advantageous in that it makes easy grasping of the unique characteristics of each category [9]. Hence, Logistic Regression Analysis is applicable to researches on the effect of independent variables of smart-phone customer attribution on binary dependent variables with the aim to determine whether or not there is switch intention.

For a common model of Logistic Regression Analysis, the Equation is presented in (1) below, where the number of independent explanatory variables is $n$.

logit $=\beta_{0}+\beta_{1} X_{1}+\cdots+\beta_{n} X_{n}$

Where, $\operatorname{logit}=\log (p /(1-p))$ and $p=\operatorname{Pr}(Y=1 \mid$ all $X)$. Regression models are useful in defining the dependent variable especially when the number of independent variables is relatively small [9]. Accordingly, this study utilizes explanatory factors that are based on the variables stated above, and the logistic regression model is Equation (2) below:

$\ln \left(\frac{p_{i}}{1-p_{i}}\right)=\beta_{0}+\beta_{1} X_{1}+\beta_{2} X_{2}+\cdots+\beta_{7(8)} X_{7(8)}, \mathrm{i}=1,2,3, \ldots, 7(8)$

where, $p_{i}$ is the probability that the answer regarding switch intention would be in the form of $\mathrm{No} / \mathrm{Yes}$.

\section{Research Method}

\subsection{Data Collection and Sampling}

To grasp the effect of smart-phone customer attribution on switch intention, a questionnaire-based survey was conducted among 600 adults aged 20 to 39 (300 for Galaxy; and 300 for Xiaomi) in Shanghai, China, by an internet-based survey agency named SoJump (問卷星). With 83 incomplete surveys excluded, 507 questionnaire sheets were collected and analyzed. 
Table 4-1. Basic Statistics

(Unit: Individuals, \%)

\begin{tabular}{|c|c|c|c|c|c|c|c|}
\hline \multirow{2}{*}{\multicolumn{2}{|c|}{ Classification }} & \multicolumn{2}{|c|}{ Galaxy } & \multicolumn{2}{|c|}{ Xiaomi } & \multicolumn{2}{|c|}{ Tad } \\
\hline & & Frequency & Percentage & Frequency & Percentage & Frequency & Percentage \\
\hline \multirow{2}{*}{ Sex } & Male & 129 & 51.8 & 132 & 51.2 & 261 & 51.5 \\
\hline & Female & 120 & 48.2 & 126 & 48.8 & 246 & 48.5 \\
\hline \multirow{2}{*}{ Age } & $20 \sim 29$ & 120 & 48.2 & 164 & 63.6 & 284 & 56.0 \\
\hline & $30 \sim 39$ & 129 & 51.8 & 94 & 36.4 & 223 & 44.0 \\
\hline \multirow{6}{*}{ Income } & Under 3000RMB & 9 & 3.6 & 14 & 5.4 & 23 & 4.5 \\
\hline & $3001 \sim 5000 \mathrm{RMB}$ & 63 & 25.3 & 47 & 18.2 & 110 & 21.7 \\
\hline & $5001 \sim 7000 \mathrm{RMB}$ & 64 & 25.7 & 51 & 19.8 & 115 & 22.7 \\
\hline & $7001 \sim 10000 \mathrm{RMB}$ & 65 & 26.1 & 75 & 29.1 & 140 & 27.6 \\
\hline & $10001 \sim 15000 \mathrm{RMB}$ & 32 & 12.9 & 55 & 21.3 & 87 & 17.2 \\
\hline & Over 15001RMB & 16 & 6.4 & 16 & 6.2 & 32 & 6.3 \\
\hline \multicolumn{2}{|r|}{ Total } & 249 & 100 & 258 & 100 & 507 & 100 \\
\hline
\end{tabular}

\subsection{Variables}

Measurement items used in this study had been demonstrated in the preceding research, and all items except demographic items were utilized in a way of direct questions by means of a 5-point Likert Scale.

※ Brand Type: 1 . Galaxy, 2. Xiaomi

※ Questions about smart-phone customer attribution and switch intention

\begin{tabular}{|c|c|}
\hline Item & Notd Yes \\
\hline 1. Galaxy/Xiaomi is worth the money that I paid & (1) - (2) - (3) - (4) - (5) \\
\hline 2. Galaxy/Xiaomi is worth the time that I use for it & (1) - (2) - (3) - (4) - (5) \\
\hline 3. I am satisfied with Galaxy/Xiaomi more than other brands & (1) - (2) - (3) - (4) - (5) \\
\hline $\begin{array}{l}\text { 4. Smart-phones of Galaxy/Xiaomi are more reliable than those } \\
\text { of otherbrands }\end{array}$ & (1) - (2) - (3) - (4) - (5) \\
\hline $\begin{array}{l}\text { 5. Smart-phone information from Galaxy/Xiaomi is more reliable } \\
\text { than that fromother brands }\end{array}$ & (1) - (2) - (3)- (4)- (5) \\
\hline 6. Iam happy to purchase Galaxy/Xiaomi smart-phone products & (1) - (2) - (3) - (4) - (5) \\
\hline 7. I have a strong sense of belonging to Galaxy/Xiaomi. & (1) - (2) - (3) - (4) - (5) \\
\hline $\begin{array}{l}\text { 8. I may select a new smart-phone brand other than } \\
\text { Galaxy/Xiaomi in the future }\end{array}$ & $(1)-(2)-(3)-(4)-(5)$ \\
\hline
\end{tabular}




\section{Empirical Analysis}

For empirical analysis, this study takes advantage of SPSS 22.0, which is useful for Logistic Regression Analysis. This analysis was conducted among smart-phone consumers in China who were using Galaxy and/or Xiaomi to examine the effect on switch intention. For binary parametric conversion of switch intention, which was a dependent variable, the value or 3 (yes) or less was interpreted as "no switch intention" and the value over 3 as "switch intention."

\subsection{Overview of the Model}

To verify the statistical significance of the model, $-2 \mathrm{LL}$ and Chi-square values of each model were examined. As shown in <Table 5-1>, -2LL values of Galaxy, Xiaomi, and Total were $315.817,300.248$, and 626.889 , respectively. Values of Chi-square were $24.984,25.351$, and 45.822 , respectively. As the significance probability of the model coefficient was lower than 0.001 in general, and when the probability was 0.5 , the model was viewed as significant.

Table 5-1. Model Overview

\begin{tabular}{c|c|c|c}
\hline & $-2 \mathrm{LL}$ & Chi-square & P-value \\
\hline Galaxy & 315.817 & 24.984 & 0.001 \\
\hline Xiaomi & 300.248 & 25.351 & 0.001 \\
\hline Total & 626.889 & 45.822 & 0.000 \\
\hline
\end{tabular}

As $\langle$ Table 5-2> shows, the distribution of switch intention among Galaxy users, the classification accuracy of 'No' (no switch intention) was 77.3\% and that of 'Yes' (switch intention) $46.3 \%$. The general prediction probability was $63.9 \%$.

Table 5-2. Distribution of Switch Intention (Galaxy)

\begin{tabular}{|c|c|c|c|c|}
\hline \multirow{3}{*}{\multicolumn{2}{|c|}{ Monitoring }} & \multicolumn{3}{|c|}{ Prediction } \\
\hline & & \multicolumn{2}{|c|}{ Brand Switching } & \multirow{2}{*}{$\begin{array}{l}\text { Classification } \\
\text { Accuracy(\%) }\end{array}$} \\
\hline & & No & Yes & \\
\hline \multirow{2}{*}{ Brand Switching } & No & 109 & 32 & 77.3 \\
\hline & Yes & 58 & 50 & 46.3 \\
\hline \multicolumn{2}{|c|}{ Total } & & & 63.9 \\
\hline
\end{tabular}

As $\langle$ Table 5-3> shows, the distribution of switch intention among Xiaomi users, the classification accuracy of 'No' was $88.9 \%$, and that of 'Yes' $20.2 \%$. The general prediction probability was $68.2 \%$. 
Table 5-3. Distribution of Switch Intention (Xiaomi)

\begin{tabular}{|c|c|c|c|c|}
\hline \multirow{3}{*}{\multicolumn{2}{|c|}{ Monitoring }} & \multicolumn{3}{|c|}{ Prediction } \\
\hline & & \multicolumn{2}{|c|}{ Brand Switching } & \multirow{2}{*}{$\begin{array}{l}\text { Classification } \\
\text { Accuracy }(\%)\end{array}$} \\
\hline & & No & Yes & \\
\hline \multirow{2}{*}{ Brand Switching } & No & 159 & 15 & 91.4 \\
\hline & Yes & 67 & 17 & 20.2 \\
\hline \multicolumn{2}{|c|}{ Total } & & & 68.2 \\
\hline
\end{tabular}

As <Table 5-4> shows, the distribution of switch intention among all, the classification accuracy of 'No'was $88.9 \%$, and that of 'Yes'29.7\%. The general prediction probability was $66.5 \%$.

Table 5-4. Distribution of Switch Intention (Total)

\begin{tabular}{|c|c|c|c|c|}
\hline \multirow{3}{*}{\multicolumn{2}{|c|}{ Monitoring }} & \multicolumn{3}{|c|}{ Prediction } \\
\hline & & \multicolumn{2}{|c|}{ Brand Switching } & \multirow{2}{*}{$\begin{array}{l}\text { Classification } \\
\text { Accuracy }(\%)\end{array}$} \\
\hline & & No & Yes & \\
\hline \multirow{2}{*}{ Brand Switching } & No & 280 & 35 & 88.9 \\
\hline & Yes & 135 & 57 & 29.7 \\
\hline \multicolumn{2}{|c|}{ Total } & & & 66.5 \\
\hline
\end{tabular}

\section{2 Result of Logistic Regression Analysis}

As a result of the Logistic Regression Analysis conducted to examine smart-phone customer attributes that affect switch intention, which is a dependent variable, the final logistic regression models were Equation(3), Equation(4), and Equation(5). The results

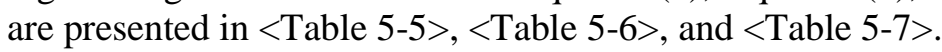

$$
\left.\ln \left(\frac{p_{i}}{1-p_{i}}\right)=1.623+0.673(\text { Non }- \text { monetary Value })-0.623 \text { (Product Trust }\right)-0.377 \text { (Commitment) }
$$

Table 5-5. Variables in the Equation (switch intention_Galaxy)

\begin{tabular}{c|c|c|c|c|c|c}
\hline & B & S.E. & Wals & $\begin{array}{c}\text { Degreof } \\
\text { Freedom }\end{array}$ & $\begin{array}{c}\text { Significance } \\
\text { Probability }\end{array}$ & Exp(B) \\
\hline Monetary value & -0.101 & 0.254 & 0.158 & 1 & 0.691 & 0.904 \\
\hline Non-monetary value & 0.673 & 0.223 & 9.108 & 1 & $0.003^{*}$ & 1.961 \\
\hline User satisfaction & -0.313 & 0.255 & 1.508 & 1 & 0.219 & 0.731 \\
\hline Product Trust & -0.623 & 0.263 & 5.618 & 1 & $0.018^{*}$ & 0.537 \\
\hline Information Trust & 0.361 & 0.260 & 1.922 & 1 & 0.166 & 1.434 \\
\hline Attachment & -0.111 & 0.196 & 0.320 & 1 & 0.572 & 0.895 \\
\hline Commitment & -0.377 & 0.182 & 4.283 & 1 & $0.039^{* *}$ & 0.686 \\
\hline Constant Term & 1.623 & 1.144 & 2.011 & 1 & 0.156 & 5.066 \\
\hline Notes : $p<0.01, \quad p<0.05, \quad p\langle 0.1$ & & & &
\end{tabular}


As a result of the Logistic Regression Analysis on the 7 attributes related to switch intension of Galaxy users, it turned out that non-monetary value, product trust, and commitment were statistically significant in the significance level of, and that the rest were statistically insignificant in the significance level of.

Specifically, of the non-monetary value related to switch intention was 1.961 . When the non-monetary value increased as much as 1 unit, the probability that switch intention would increase among Galaxy users increased as much as 1.961 times. Of product trust was 0.537 , and when the product trust increased as much as 1 unit, the probability that switch intention would decrease among Galaxy users increased as much as 0.537 times. Of commitment was 0.686 . As the absorption increased as much as 1 unit, the probability that switch intention would decrease among Galaxy users increased as much as 0.686 times.

$$
\left.\ln \left(\frac{p_{i}}{1-p_{i}}\right)=4.348-1.492(\text { User Satisfaction })-0.628 \text { (Product Trust }\right)-0.459 \text { (Commitment) }
$$

Table 5-6. Variables in the Equation (switch intention_Xiaomi)

\begin{tabular}{c|c|c|c|c|c|c}
\hline & B & S.E. & Wals & $\begin{array}{c}\text { Degree of } \\
\text { Freedom }\end{array}$ & $\begin{array}{c}\text { Significance } \\
\text { Probability }\end{array}$ & Exp(B) \\
\hline Monetary value & 0.160 & 0.260 & 0.381 & 1 & 0.537 & 1.174 \\
\hline Non-monetary value & -0.185 & 0.216 & 0.740 & 1 & 0.390 & 0.831 \\
\hline User satisfaction & -0.492 & 0.258 & 3.623 & 1 & $0.057^{* * *}$ & 0.611 \\
\hline Product Trust & -0.628 & 0.281 & 5.008 & 1 & $0.025^{* *}$ & 0.534 \\
\hline Information Trust & 0.284 & 0.261 & 1.182 & 1 & 0.277 & 1.328 \\
\hline Attachment & 0.035 & 0.202 & 0.030 & 1 & 0.862 & 1.036 \\
\hline Commitment & -0.459 & 0.199 & 5.316 & 1 & $0.021^{* *}$ & 0.632 \\
\hline Constant term & 4.348 & 1.391 & 9.774 & 1 & $0.002^{*}$ & 77.319 \\
\hline Notes : ${ }^{*} p<0.01, \quad p<0.05, \quad p<0.1$ & & & & &
\end{tabular}

As a result of the Logistic Regression Analysis regarding the 7 attributes of Xiaomi user switch intention, it turned out that user satisfaction, product trust, and commitment were statistically significant at the significance level of while the rest were not statistically significant at the significance level of.

Specifically, of the user satisfaction value related to switch intention was 0.611 . When the user satisfaction value increased as much as 1 unit, the probability that switch intention would decrease among Xiaomi users increased as much as 0.611 times. Of product trust was 0.543 , and when the product trust increased as much as 1 unit, the probability that switch intention would decrease among Xiaomi users increased as much as 0.543 times. Of commitment was 0.632 . As commitment increased as much as 1 unit, the probability that switch intention would decrease among Xiaomi users increased as much as 0.632 times.

$$
\begin{aligned}
& \left.\left.\ln \left(\frac{p_{i}}{1-p_{i}}\right)=2.521-0.366 \text { (User Satisfaction }\right)-0.624 \text { (Product Trust }\right)-0.368 \text { (Commitment) } \\
& +0.366 \text { (Galaxu) }
\end{aligned}
$$


Table 5-7. Variables in the Equation (switch intention_Total)

\begin{tabular}{c|c|c|c|c|c|c}
\hline & B & S.E. & Wals & $\begin{array}{c}\text { Degree of } \\
\text { Freedom }\end{array}$ & $\begin{array}{c}\text { Significance } \\
\text { Probability }\end{array}$ & Exp(B) \\
\hline Monetary value & 0.085 & 0.176 & 0.234 & 1 & 0.628 & 1.089 \\
\hline Non-monetary value & 0.240 & 0.150 & 2.536 & 1 & 0.111 & 1.271 \\
\hline User satisfaction & -0.366 & 0.177 & 4.280 & 1 & $0.039^{* *}$ & 0.693 \\
\hline Product Trust & -0.624 & 0.189 & 10.871 & 1 & $0.001^{*}$ & 0.536 \\
\hline Information Trust & 0.278 & 0.181 & 2.350 & 1 & 0.125 & 1.321 \\
\hline Attachment & -0.062 & 0.138 & 0.201 & 1 & 0.654 & 0.940 \\
\hline Commitment & -0.368 & 0.131 & 7.845 & 1 & $0.005^{*}$ & 0.692 \\
\hline Brand type & 0.366 & 0.201 & 3.328 & 1 & $0.068^{* * *}$ & 1.442 \\
\hline Constant term & 2.521 & 0.891 & 8.001 & 1 & $0.005^{*}$ & 12.445 \\
\hline Notes : ${ }^{*} p<0.01,{ }^{* *} p$ & \multicolumn{2}{|c|}{${ }^{* * *} p\langle 0.1$} & & & &
\end{tabular}

As a result of the Logistic Regression Analysis on the 8 attributes related to the general user switch intention, it turned out that user satisfaction, product trust, commitment, and brand types were statistically significant at the significance level of alpha $=0.1$ while the rest were statistically insignificant at the significance level of alpha $=0.1$.

Specifically, Exp (beta) of the user satisfaction value related to switch intention was 0.693 . When the user satisfaction value increased as much as 1 unit, the probability that switch intention would decrease among general users increased as much as 0.693 times. Exp (beta) of product trust was 0.536 , and when the product trust increased as much as 1 unit, the probability that switch intention would decrease among general users increased as much as 0.536 times. Exp (beta) of commitment was 0.692. As commitment increased as much as 1 unit, the probability that switch intention would decrease among general users increased as much as 0.692 times. Lastly, it turned out that the brand type analysis shows that as the use of Galaxy/Xiaomi increased as much as 1 unit, switch intention of Xiaomi users was 0.366 times higher than that of Galaxy users.

\section{Conclusion}

\subsection{Research Findings and Significance}

This is a research on switch intention after purchase among Chinese customers. The objective of this study is to examine the effect of the monetary value, non-monetary value, user satisfaction, product trust, information reliability, attachment, commitment, and brand types among smart-phone users on their switch intention in order to clarify its significance in policies for the Chinese smart-phone industry. Accordingly, a questionnaire-based survey was conducted by an internet-based research agency among users of Xiaomi that was leading the Chinese smart-phone market and Samsung Galaxy that aimed to secure market shares in the Chinese smart-phone market as well as the global market. The results were examined using Logistic Regression Analysis.

First of all, with regard to the model of Logistic Regression Analysis on Galaxy, Xiaomi, and general smart-phone customers, the general test significance probability of the model coefficients was all under 0.001, and when the value of Significance Probability was 0.5 , the model was viewed as significant. The results of Logistic Regression Analysis on each model are as follows: First, in the analysis of the 7 attributes 
of switch intention among Galaxy users, non-monetary value, product trust, and commitment were statistically significant at the significance level of while the rest were statistically insignificant at the significance level of. Second, in the analysis of the 7 attributes related to switch intention among Xiaomi users, it turned out that user satisfaction, product trust, and commitment were statistically significant at the significance level of while the rest were statistically insignificant at the significance level of. Lastly, in the analysis of the 8 attributes related to switch intention of the general users, user satisfaction, product trust, commitment, and brand types were statistically significant in the significance level of while the rest were statistically insignificant at the significance level of.

As mentioned in the findings above, this study is practically significant in the following aspects: First, smart-phone manufacturers which have advanced and run businesses in the Chinese smart-phone market need to grasp switch intention among Chinese customers accurately. It turned out that switch intention of Chinese smart-phone customers were affected by such factors as smart-phone user satisfaction, product trust, commitment, and brand types. Switch barriers need to be established based on these findings. In comparison to the global sales of smart-phones with sales in China, the sales in China accounted for $41.3 \%$ of the entire smart-phone sales in the world during the second quarter of 2015. This indicates that for smart-phone manufacturers to increase their general sales profit, increasing shares in the Chinese market is of importance. In addition, marketing strategies aimed at the Indian smart-phone market are necessary as well. Second, smart-phone manufacturers need to grasp factors that affect switch intention of brands of their own and of their competitors.

As for Galaxy, it turned out that non-monetary value, product trust, and commitment affected switch intention. As for Xiaomi, user satisfaction, product trust, and commitment affected switch intention. This result indicates that Galaxy needs to strengthen its nonmonetary value while Xiaomi needs to strengthen its user satisfaction in order to decrease switch intention among their own customers. Lastly, it is necessary to put forth efforts to enhance product trust and commitment among Chinese customers. Since it is expected that lack of reliability and commitment in certain products would result in switch among customers in China, smart-phone manufacturers need to take measures accordingly.

In theoretical aspects, this study is significant in that while existing researches focus on processes as a factor that would affect switch intention with little attention to the judgment and prediction of switch behaviors, this study presents a theoretical basis for the establishment of switch barriers by suggesting predictive models of switch behaviors on the basis of customer attribution of switch intention in supplementation of existing researches. Additionally, as the level of switch intention prediction of the Logistic Regression Analysis turned out to be generally low, further efforts need to be put forth into improving it. Finding out consumer attributes will be an important issue for future researches. To grasp customer intentions in this era of big data, it is necessary to grasp elements that would satisfy consumer needs in utilization of internet-based searching methods. For instance, web searching for reviews of smart-phone brand users will be useful in grasping customer desires in the smart-phone industry and establishing strategies accordingly, which will contribute to developing models for better results and predictions.

\subsection{Limitations and Future Direction of Research}

This study is significant in that the findings are useful for Xiaomi and Samsung to ensure customers who are considering brand switching and to increase market shares in the Chinese smart-phone market. However, it also involves the following limitations:

First, since this study limits the scope of smart-phone customers in China to users of Xiaomi and Samsung Galaxy, Wuawei which is dominating the Chinese smart-phone market and Apple which is competing with Samsung in the global market are not taken 
into consideration. Thus, future researches need to compare the effects of smart-phone customer attribution on switch intention among customers of various smart-phone manufacturers in global as well as Chinese markets.

Second, this study utilizes the direct questioning method in the Logistic Regression Analysis of the effect of customer attribution on switch intention among smart-phone users in China. While multiple questions were asked on each attribute, there was no question that took into consideration various situations. Thus, it is necessary to measure variables of each factor in a way of multi-variate analysis in examining variables such as monetary value, non-monetary value, user satisfaction, product trust, information reliability, attachment, and commitment.

Third, this study analyzes switch intention based on attributes of smart-phone customers in China. In contrast, there is no research on switch intention among multinational customers such as those in Korea and Japan. In general, smart-phone manufacturers aim at various countries as well as the domestic market, and thus researches on the effects of consumer attributes that reflect cultures and local characteristics on switch intention will produce substantial data necessary for smartphone manufacturers to increase their global market shares, which is thus another important area of research.

\section{References}

[1] TrendForce, http://www.TrendForce.com, (2015) July.

[2] J. M. Lattin and L. McAlister, "Using a Variety-seeking Model to Identify Substitute of Complementary Relationships among Competing Products," Journal of Marketing Research, (1985) August 22, pp. 330-339.

[3] C. Fornell, "A National Customer Satisfaction Barometer: The Swedish Experience", Journal of Marketing, vol. 56, no. 1, (1992), pp. 6-21.

[4] I. Aizen, "The Theory of Planned Behavior", Organizational Behavior and Human Decision Processes, vol. 50, (1991), pp. 179-211.

[5] S. M. Keaveney, "Customer Switching Behavior in Service Industries: An Exploratory Study", Journal of Marketing, vol. 59, no. 20, (1995), pp.71-82.

[6] M. J. Bitner, "Evaluating Service Encounter: The Effects and Physical Surroundings and Employee Response", Journal of Marketing, vol. 52, no. 1, pp. 57-71.

[7] P. F. Verhulst, Notice sur la loi que la population suit dans son accroissement, Corresopndance mathematique et physique, vol. 10, no. 1838, pp. 113-125.

[8] D. G. Kleinbaum and M. Klein, "Logistic regression: a self-learning text. Springer Science \& Business Media", (2010).

[9] D. W. Hosmer and S. Lemesbow, "Goodness of fit tests for the multiple logistic regression model", Communications in statistics Theory and Methods, vol. 9, no. 10, (1980), pp. 1043-1069.

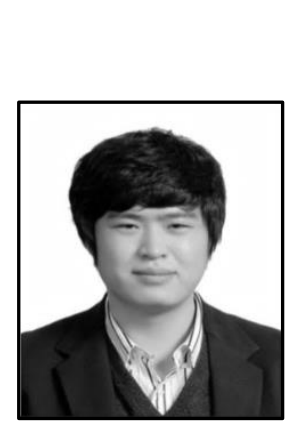

\section{Authors}

Huifeng, Pan, PhD, currently works as in Beijing Institute of Graphic Communication; Post-Doctoral Research Station in Business Administration of TsingHua University, Beijing, China. His research interests are culture marketing, consumer behavior, IT services, and communication services.

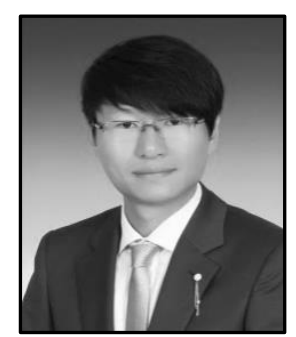

Hee-young, Son, $\mathrm{PhD}$, currently works as a senior researcher in the Korea Institute of Startup \& Entrepreneurship Development, Republic of Korea. His research focus is service marketing, and interests are related broadly to entrepreneurship from startup and small business. 


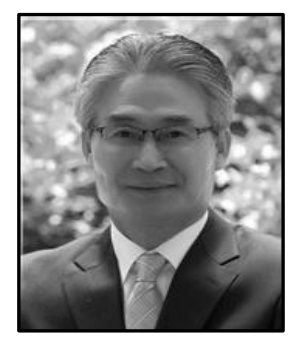

Sang-kyu, Park, PhD, A professor in the Department of Business Management, College of Business Management, Kangwon National University. Bachelor's degree and master's degree at the Department of Business Management, Kangwon National University. Master's degree of Business Administration (marketing) at Aachen University of Technology, Germany. Major areas of interests include consumer behaviors.

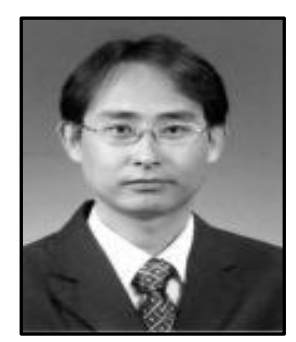

Man-su, Kang, $\mathrm{PhD}$, A responsible research fellow at the Team of Business Planning, Seoul of Credit Guarantee Foundations at present. Bachelor's degree from the Department of Business Management, Kangwon National University; Master's degree and Doctor's degree at the graduate school of the same university. Major areas of interests include small business financing, consumer behaviors, IT service, and e-business. 
International Journal of Smart Home

Vol. 11, No. 1 (2017) 